\title{
Mentoring Children through Chess Training Enhances Cognitive Functions
}

\author{
Ebenezer Joseph, Veena Easvaradoss, Suneera Abraham, and Melissa A. Chan
}

\begin{abstract}
Chess is an excellent tool for mentoring children. The present study analyzes the impact of the frequency of chess training on increases in the IQ of children. The frequency of chess training refers to the time the chess coach spends with the child and hence translates into a mentoring component. In the chess training program, the child is mentored as the chess coach works closely with the child. Two chess training programs are compared in the study - chess in schools (once a week) and chess in academy (biweekly). The chess-in-academy program had a higher level of mentoring than the chess in schools program. IQs of 61 children studying in chess academy were compared with IQs of 25 children studying chess in school. Pre- and post-chess-training IQs were assessed using Binet-Kamat Test of Intelligence. Statistical analyses were carried out. Significant IQ gains were observed in both programs, resulting in a 9-point average IQ increase in the biweekly program compared to a marginal 4-point average IQ gain in chess in the schools program. This higher impact on IQ could be attributed to the strong mentoring relationship in the biweekly program.
\end{abstract}

Index Terms-Chess training, cognitive functions, IQ, mentoring.

\section{INTRODUCTION}

Chess is an excellent tool for mentoring children. Mentoring is a formal, or "formalized informal," process whereby a child is actively engaged in acquiring new knowledge, feedback, ideas, or advice under the guidance of a more knowledgeable and experienced person. A mentor supports the mentees' involvement in a program as the world of sport and coaching may be completely new to them. The mentor helps them identify what they want to gain out of the program and gives mentees the confidence to initiate action.

Audrey Collin [1] defines mentoring as "a protected relationship in which learning and experimentation can occur, potential skills can be developed, and in which results can be measured in terms of competencies gained." In chess, the potential skills that are developed are intellectual skills and

Manuscript received September 5, 2016; revised November 5, 2016. This research was supported by the funding provided by the Department of Science and Technology, Cognitive Science Research Initiative, Government of India.

Ebenezer Joseph is with the Department of Science and Technology, Government of India, India (e-mail: emmanuelchess@ gmail.com).

Veena Easvaradoss is with the Department of Psychology, Women's Christian College, Chennai, India (e-mail: veenadoss@gmail.com).

Suneera Abraham and Melissa A. Chan are with Emmanuel Chess Centre, India (e-mail: suneera@msn.com,melissaaubriechan@gmail.com). cognitive abilities.

\section{THE BENEFITS OF INCORPORATING CHESS IN THE SCHOOL CURRICULUM}

In a Texas study [2], regular elementary students who participated in a school chess club showed twice the improvement compared to non-chess players in reading and mathematics between third and fifth grades on the Texas Assessment of Academic Skills.

A study conducted in rural India [3] examined the effect of chess training on the academic performance of middle-school children. The sample consisted of 100 students of sixth grade with an intervention group undergoing chess training and a control group. The results of the paired sample $t$-test analysis showed significant improvement in academic performances of students in English, social studies, and science subjects, after a year of training in chess skills. Similar findings by Margulies [4] reported that pupils who learn chess enjoy a significant increase in their reading skills.

A Brunswick study [5] experimenting with the addition of chess to the math curriculum used three groups of 437 fifth graders. This study found increased gains in math problem-solving and comprehension proportionate to the amount of chess in the curriculum.

Joseph et al. [6] assessed the impact of chess intervention on the IQ scores of children and analyzed the cognitive functions that contributed to the IQ gain. Eighty-six school children, boys and girls in the age group 4-15 years, undergoing chess training in academy were assessed using Binet-Kamat Test of Intelligence. Chess intervention consisted of standardized biweekly training sessions of two hours duration over a period of one year. Paired $t$-tests and regression analysis were carried out. Significant increases were observed in IQ, and regression analysis indicated that nonverbal reasoning, language, and memory significantly contributed to the dependent variable IQ.

Research has shown that chess can dramatically improve students' levels of concentration, improve problem-solving skills, and widen their thought processes [7]. Given the strong substantiation for academic impact, it is not surprising that educators have begun thinking of effective methods of integrating the game directly into the curriculum.

The objective of the study was to compare the two methodologies of chess training - chess in academy and chess in schools. This study compares two groups receiving chess training over one-year period - one group was a chess-in-school training program and the other was a chess-in-academy program. Mentoring was a component of both training programs where the chess trainer worked closely 
with the child, analyzing their games and tactical case studies. The following research questions were posed: Does mentoring and frequency of the chess intervention influence the IQ gains observed following chess training? Does the size of the training group have an impact on the changes observed in IQ?

\section{RESEARCH DESIGN}

The study used a two-group pretest-posttest comparison design. The independent variable was mentoring, that is, chess-in-school program vs. chess-in-academy program. The chess-in-academy program had higher level of mentoring (as measured by the frequency of the chess intervention and the size of the training group) than the chess-in-school program. The dependent variable was IQ.

\section{SAMPLE}

The chess-in-school program consisted of 25 boys selected purposively who chose to play chess. The chess-in-academy program consisted of 61 boys who were undergoing chess training at a chess academy. The age range of the sample was 4 to 15 years. Children whose IQs were above 140 were excluded from the sample.

\section{MeAsures}

The children were assessed using the Binet-Kamat Test of Intelligence. The Stanford revision of the test was adapted as the Binet-Kamat Test of Intelligence to suit the Indian children. The present version consists of various verbal and performance tests that can be administered to children and adults from ages 3 to 22 years. Validity of the test shows that when a fourfold table was drawn up and the correlation of the pluses and minuses of each test with mental age as obtained by the whole scale was found, the correlation coefficients of the tests were generally higher than 0.70 . Correlations between IQ (as determined by the scale) and the teacher's estimates were found to be nearly 0.50 , which is fairly high considering the variability of the teacher's estimates.

\section{PROCEDURE}

Baseline IQ assessment was done after obtaining informed consent. Reassessment was carried out after an average duration of one year.

The assessment environment was quiet without any disturbance and kept standardized. Psychologists were trained to administer the test in a uniform standardized manner to minimize the testing error.

Clustering technique was used to form the training groups. The children followed a standardized Winning Moves [8] curriculum and played in tournaments from time to time.

The chess-in-school training consisted of once-a-week chess classes conducted for one hour at the end of school hours. Training groups of six to eight children were formed following the clustering techniques. The chess classes were fixed keeping in mind the school schedule. The training was funded by the Department of Science and Technology, Government of India.

The training in chess academy consisted of biweekly sessions. Children attended classes for one to two hours at the chess centre following payment. There were eight clusters for training, and four children were assigned to each cluster along with a coach according to their playing strength, which kept changing dynamically through the year. Training groups of four children were formed following the clustering technique. Classes were scheduled throughout the year. The coaches were also assigned carefully to each group in accordance to their strength of training and their ability to communicate and interact with children of various age groups and differing strengths of chess playing. Mentoring was offered to these students in the form of closer supervision of their play, more intensive training program, one-to-one game analysis, and feedback to build their strengths and correct their weaknesses, thereby improving their meta-cognitive abilities.

\section{ChESS CURRICULUM}

The training methodology comprised of Winning Moves Chess DVD Episodes 1-22, lectures with the demonstration board, on-the-board playing and training, chess exercise through workbooks (chess school 1A, chess school 2, and tactics), and working with chess software's. Further student games were mapped using Chess Base software, and the brain patterns of the children were understood. They were taught the ideas behind chess openings, and exposure to classical games was also given. The children participated in mock as well as regular tournaments.

\section{RESULTS}

The data were analyzed, and equivalence of pre intervention IQs was established between the two groups using the student's $t$-test.

TABLE I: SHOWING THE PRE-INTERVENTION EQUIVALENCE OF CHESS IN SCHOOLS AND CHESS-IN-ACADEMY GROUPS USING INDEPENDENT $T$-TEST

\begin{tabular}{|l|c|c|c|c|}
\hline Groups & $n$ & \multicolumn{2}{|c|}{ Pre-intervention IQ } & \multirow{2}{*}{$t$} \\
\cline { 4 - 5 } & & Mean & SD & \\
\hline $\begin{array}{l}\text { Chess in } \\
\text { schools }\end{array}$ & 25 & 116.47 & 17.45 & \\
\hline $\begin{array}{l}\text { Chess in } \\
\text { academy }\end{array}$ & 61 & 119.984 & 11.49 & \\
\hline
\end{tabular}

Table I indicates that there is no significant difference in pre-intervention IQs of the two groups, thus establishing their equivalence.

Table II comparing the post-intervention IQs shows that the chess-in-academy group has significantly greater gains ( $p$ $<.05)$ in IQ compared to the chess-in-school group.

Paired $t$-test was used to compare the significance of the difference between means for the pre- and post-intervention IQs for the chess-in-school group and the chess-in-academy group (Table III). There was a significant difference between the pre- and post-intervention IQ scores for the students in chess-in-academy program at 0.01 level. 
TABLE II: SHOWING THE POST-INTERVENTION COMPARISON OF THE TWO GROUPS USING INDEPENDENT $T$-TEST

\begin{tabular}{|l|c|c|c|c|}
\hline \multirow{2}{*}{ Groups } & $N$ & \multicolumn{2}{|c|}{ Post-intervention IQ } & \multirow{2}{*}{$t$} \\
\cline { 3 - 5 } & & Mean & SD & \\
\hline $\begin{array}{l}\text { Chess in } \\
\text { schools }\end{array}$ & 25 & 120.88 & 18.12 & \multirow{2}{*}{$2.28 *$} \\
\hline $\begin{array}{l}\text { Chess in } \\
\text { academy } \\
* p<.05\end{array}$ & 61 & 128.9 & 13.26 & \\
\hline
\end{tabular}

TABLE III: COMPARISON OF THE PRE- AND POST-INTERVENTION IQS WITHIN EACH GROUP USING THE PAIRED $T$-TEST

\begin{tabular}{|c|c|c|c|c|c|}
\hline \multirow{2}{*}{ Groups } & \multicolumn{2}{|c|}{ Mean IQ and SD } & \multicolumn{2}{|c|}{$\begin{array}{l}\text { Standard Error of } \\
\text { Mean }\end{array}$} & \multirow{2}{*}{$t$} \\
\hline & Pre-test & Post-test & Pre-test & Post-test & \\
\hline $\begin{array}{l}\text { Chess in } \\
\text { schools }\end{array}$ & $\begin{array}{l}116.474 \\
(17.45)\end{array}$ & $\begin{array}{l}120.889 \\
(18.12)\end{array}$ & 3.490 & 3.624 & $1.739 *$ \\
\hline $\begin{array}{l}\text { Chess in } \\
\text { academy }\end{array}$ & $\begin{array}{c}119.983 \\
(11.49)\end{array}$ & $\begin{array}{c}128.907 \\
(13.26)\end{array}$ & 1.496 & 1.69 & $5.320 * *$ \\
\hline
\end{tabular}

There was a significant difference between the pre- and post-intervention IQ scores for the students in chess-in-school program at 0.05 level but not at 0.01 level.

\section{DISCUSSION}

In this study, chess intervention has led to significant IQ gains in both the chess-in-school program and the chess-in-academy training program. Both methodologies of chess training have effectively led to an enhancement of cognitive functioning as measured by IQ. Table III shows that there was a four-point mean IQ gain in the chess-in-school program, which was statistically significant at $p<.05$ level only. On the other hand, in the chess-in-academy training, there was a nine-point mean IQ gain, which was statistically significant at $p<.01$ level. It is clearly evident that the chess-in-academy intervention was more effective.

It appears that merely playing the games does not impact cognitive skills greatly. It may produce game-playing skills, but for cognitive functions to be significantly impacted, active processing, self-evaluation, and feedback from the coach are required in the context of a mentoring relationship. Thus, the greater gain could be attributed to the frequency of the sessions, intensity of the chess training, and the mentoring relationship.

Two research studies were undertaken by Fried and Ginsburg [9] and Hong and Bart [10]. Their results stated that the cognitive improvement following chess training was not statistically significant. It is to be noted that Fried and Ginsburg's sample, which included students of fourth and fifth grades of both genders, underwent only 18 sessions in an academic year. In the second study [10], the sample consisted of students aged between 8 and 12 years of both genders who underwent chess intervention only for 12 sessions in an academic year.

The positive impact of frequent training sessions is seen in another study by Kazemi et al. [11]. Their research reported a significant impact of chess training on cognition. The sample included male students of fifth, eighth, and ninth grades who underwent chess intervention for 6 months. So it appears that at least 25-30 sessions per year are required to see a significant gain in cognition.

The children trained in the present study worked on tactical studies, end-game techniques, and chess playing with analysis. Such focused chess intervention developed the meta-cognitive skills, sharpening cognitive patterns and improving precision in calculation. This enhanced cognitive ability probably improved their scores on the psychometric test.

The chess training curriculum used in the present study includes workbooks, score sheet writing, the Winning Moves Chess DVD, and various softwares for solving case studies and playing chess. Utilization of this multi-strategy curriculum can build up the child's critical thinking skills, strategizing, and long-range planning.

The one-to-one game analysis, which is an important component of the mentoring approach at the chess center, ensures that the child thinks about his or her game playing retrospectively and is intensely cognitively engaged in weighing options, evaluating outcomes, and making decisions. These activities strengthen the executive functions and meta-cognitive abilities in children. The biweekly sessions further increased the practice of these skills.

\section{IMPLICATIONS}

Chess training clearly enhances intellectual functioning in children. However, this increase is mediated by the strength of the program in terms of the mentoring provided by the chess trainer. When chess training is delivered frequently and more intensely with a strong mentoring component of close supervision, game analyses, and feedback, cognitive skills are strengthened. The chess coach and the training curriculum play a pivotal role in this process. When systematic chess training in chess-in-school program with proper curriculum and chess coaches who are equipped with expertise chess and mentoring skills is offered, one could expect a significant increase in IQ.

\section{REFERENCES}

[1] A. Collin, "Mentoring," Industrial Comm. Training, vol. 20, no. 2, pp. 23-27, 1988.

[2] J. Liptrap, "Chess and standardized test scores," Chess Coach Newsletter, vol. 11, no. 1, pp. 5, 7, Spring 1999.

[3] E. Joseph, V. Easvaradoss, and J. N. Solomon, "Impact of chess training on academic performance of rural Indian school children," Open J. Social Sci., vol. 4, pp. 20-24, 2016.

[4] S. Margulies, "The effect of chess on reading scores: District nine chess program second year report," The American Chess Foundation, New York, 1992.

[5] L. Gaudreau, A Study Comparing the Challenging Mathematics Curriculum to Traditional Math, Montreal: La Chenelière \& McGraw Hill, 1992.

[6] E. Joseph, V. Easvaradoss, A. Kennedy, and E. J. Kezia, "Chess training improves cognition in children," GSTF Journal of Psychology, vol. 2, no. 2, pp. 1-6, 2016. 
[7] G. Paton, "Chess 'should be compulsory in primary schools"," The Telegraph, 2014.

[8] E. Joseph, Patent No. L-32958/2009, 2008, India.

[9] S. Fried and N. Ginsburg, "The effect of learning to play chess on cognitive, perceptual, and emotional development in children," 2006

[10] S. Hong and W. Bart, "Cognitive effects of chess instruction on students at risk for academic failure," Int. J. Spec. Educ., vol. 22, pp. 89-96, 2007.

[11] F. Kazemi, M. Yektayar, and A. M. B. Abad, "Investigation of the impact of chess play on developing meta-cognitive ability and math problem-solving power of students at different levels of education," Procedia Social Behav. Sci., vol. 32, pp. 372-379, 2012.

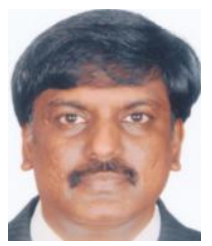

Ebenezer Joseph is India's first FIDE trainer and candidate master of the World Chess Federation. He is the principal investigator of Government of India-funded Cognitive Science Research project titled "Influence of chess training on comprehensive cognitive development of children." $\mathrm{He}$ is the founder of Emmanuel Chess Centre and has trained more than 5,000 children and 125 chess trainers in the past 20 years. He is a senior auditor in the Indian government and part-time research scholar in Madras University.

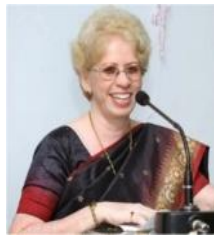

Veena Easvaradoss is associate professor and head of the Psychology Department, Women's Christian College, Chennai, India. She is a professional clinical psychologist whose research interests includes evaluation of the effectiveness of clinical counseling and special educational interventions in normal and clinical groups and test construction to measure psychosocial functions and positive psychology and mental health. She is the co-investigator of Government of India-funded Department of Science and Technology project.

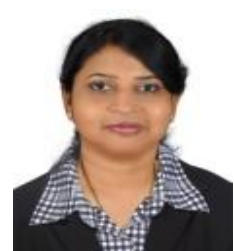

Suneera Abraham serves as a general manager (admin and international relations) in Emmanue Chess Centre. She has been involved in planning chess-in-school program, training the chess trainers program, and training children in academy for the past 16 years. Her expertise is in managing chess trainers and psychologists in the research project.

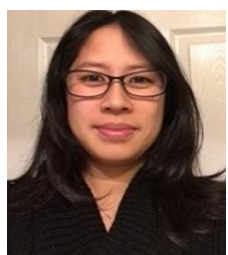

Melissa A. Chan served as a consultant and developed a long-term strategy for Emmanuel Chess Centre. She is a senior project manager at a top consumer electronics company. 